\title{
Field Data Report for the First Microwave Water and Energy Balance Experiment (MicroWEX-1), July 17 - December 16, 2003, Citra, Florida1
}

\author{
Kai-Jen Calvin Tien, Jasmeet Judge, Larry W. Miller, and Orlando L. Lanni²
}

\section{INTRODUCTION}

For accurate prediction of weather and near-term climate, root-zone soil moisture is one of the most crucial components driving the surface hydrological processes. Soil moisture in the top meter is also very important because it governs moisture and energy fluxes at the land-atmosphere interface and it plays a significant role in partitioning of the precipitation into runoff and infiltration.

Energy and moisture fluxes at the land surface can be estimated by

Soil-Vegetation-Atmosphere-Transfer (SVAT)

models. These models are typically used in conjunction with climate prediction models and hydrological models. Even though the biophysics of moisture and energy transport is well-captured in most current SVAT models, the computational errors accumulate over time and the model estimates of soil moisture diverge from reality. One promising way to significantly improve model estimates of soil moisture is by assimilating remotely sensed data that is sensitive to soil moisture, for example microwave brightness temperatures, and updating the model state variables.

The microwave brightness at low frequencies (< $10 \mathrm{GHz}$ ) is very sensitive to soil moisture in the top few centimeters in most vegetated surfaces. Many studies have been conducted in agricultural areas such as bare soil, grass, soybean, wheat, pasture, and corn to understand the relationship between soil moisture and microwave remote sensing. Most of these experiments conducted in agricultural regions have been short-term experiments that captured only a part of growing seasons. It is important to know how microwave brightness signature varies with soil moisture, evapotranspiration (ET), and biomass in a dynamic agricultural canopy with a significant biomass $\left(4-6 \mathrm{~kg} / \mathrm{m}^{2}\right)$ throughout the growing season.

\section{OBJECTIVES}

The goal of MicroWEX-1 was to investigate the interactions between the microwave brightness

1. This document is Circular 1470, one of a series of the Agricultural and Biological Engineering Department, Agricultural Research Station, Institute of Food and Agricultural Sciences, University of Florida. First published April 2005. Please visit the EDIS Web site at http://edis.ifas.ufl.edu.

2. Kai-Jen Calvin Tien, Graduate Research Assistant, Jasmeet Judge, Assistant Professor and Director of Center for Remote Sensing, Larry W. Miller, Engineer, and Orlando L. Lanni, Engineer, Department of Agricultural and Biological Engineering, Institute of Food and Agricultural Sciences, University of Florida, Gainesville, 32611.

The Institute of Food and Agricultural Sciences (IFAS) is an Equal Opportunity Institution authorized to provide research, educational information and other services only to individuals and institutions that function with non-discrimination with respect to race, creed, color, religion, age, disability, sex, sexual orientation, marital status, national origin, political opinions or affiliations. U.S. Department of Agriculture, Cooperative Extension Service, University of Florida, IFAS, Florida A. \& M. University Cooperative Extension Program, and Boards of County Commissioners Cooperating. Larry Arrington, Dean 
signatures, land surface conditions, energy components, and hydrologic processes for the entire growing season of cotton. The data collected from this field experiment will be use to relate the surface fluxes to the passive microwave signatures at 6.7 $\mathrm{GHz}$, matching that of the space borne microwave radiometer Advanced Microwave Scanning Radiometer (AMSR). Specific objectives of this field experiment are:

1.To collect a comprehensive dataset which includes passive microwave observations and other micro-meteorological data to develop and calibrate a dynamic microwave brightness (MB) model for cotton,

2. To collect moisture and energy flux data at land surface and in soil to develop a dynamic SVAT model for cotton.

\section{FIELD SETUP}

MicroWEX-1 was conducted by the Center for Remote Sensing, Agricultural and Biological Engineering Department at the Plant Science Research and Education Unit, IFAS, Citra, FL. Figure 1 and 2 show the location of the PSREU and the study site for the MicroWEX-1, respectively. The study site was located at the east side of the PSERU close to lake Orange. The lake was dried out and covered with grass during the MicroWEX-1. The dimensions of the study site were a $130 \mathrm{~m} \mathrm{X} 75 \mathrm{~m}$. A linear move system was used for irrigation. The cotton was planted on July 9 (Day of Year in 2003, DoY 190) at an orientation $60^{\circ}$ from East as shown in Figure 3. The crop spacing was about $4 \mathrm{~cm}$ and the row spacing was $90 \mathrm{~cm}$. Instrument installation took place on July 17 (DoY 198). The instruments consisted of a ground-based microwave radiometer system and micrometeorological stations. The ground-based microwave radiometer system was installed at the middle of the north edge of the site facing south to avoid the radiometer shadow interfering the field of view as seen in Figure 3.

The micrometeorological station was installed at the center of the field and included soil moisture and temperature probes, soil heat flux plates, thermal infrared sensor, net radiometer, and raingauges. Two additional raingauges also were installed at the east

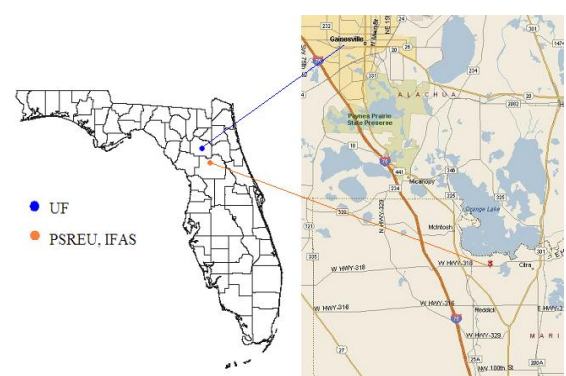

Figure 1. Location of PSREU/IFAS. Credits: IFAS Plant Sciences Research and Education Unit

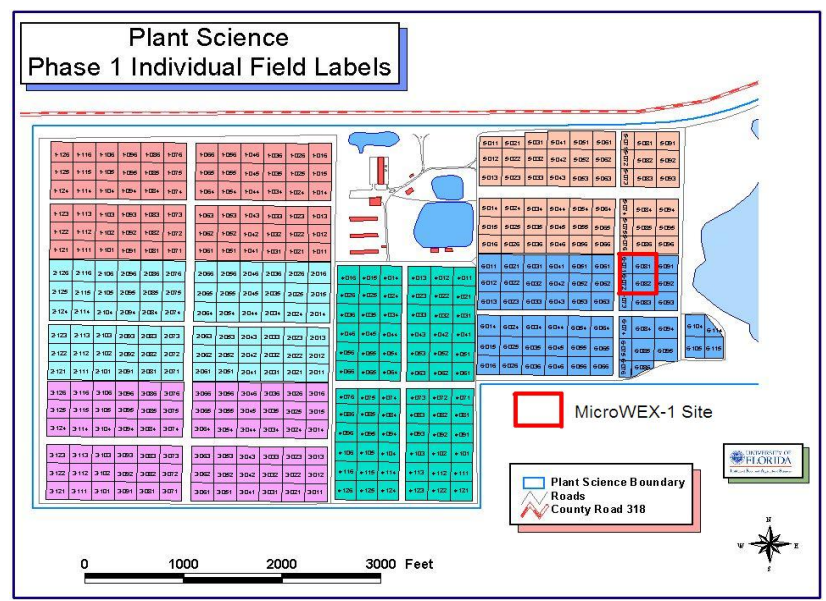

Figure 2. Location of the field site for MicroWEX-1 at the UF/IFAS PSREU. Credits: IFAS Plant Sciences Research and Education Unit

and west edge of the radiometer footprint to capture the irrigation. Later an eddy covariance system was installed at the northeast corner of the site on August 15 (DoY 227). This report provides detailed information regarding sensors deployed and data collected during the MicroWEX-1.

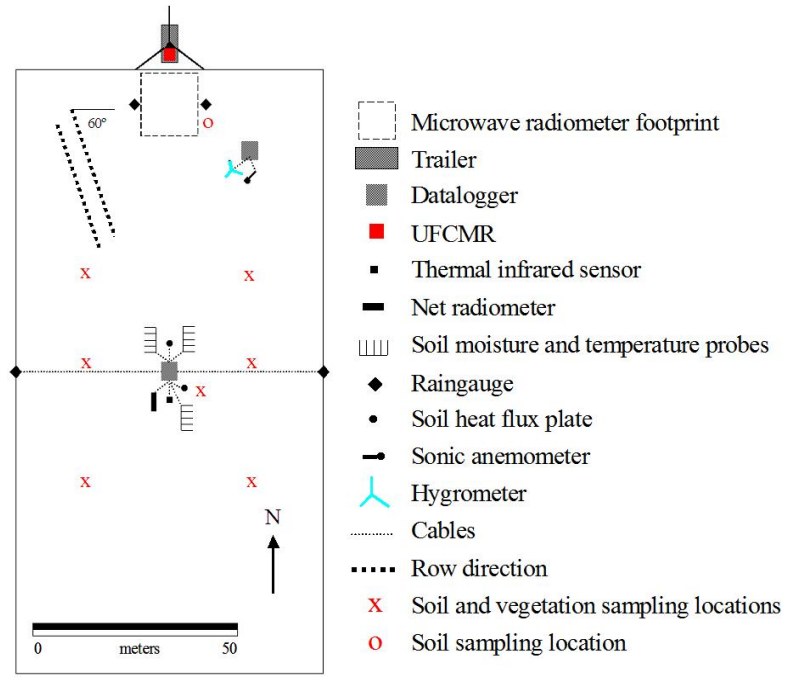

Figure 3. Layout of the sensors during MicroWEX-1. Credits: Calvin Tien 


\section{SENSORS}

MicroWEX-1 had two major instrument subsystem: the ground-based University of Florida C-band Radiometer (UFCMR) and the micrometeorological subsystems, a collection of commercially available instruments.

\subsection{University of Florida C-band Microwave Radiometer (UFCMR) System}

Microwave brightness temperatures at $6.7 \mathrm{GHz}$ (lambda $=4.48 \mathrm{~cm}$ ) were measured every 30 minutes using the University of Floridas C-band Microwave Radiometer system (UFCMR) (Figure 4 (a)). The radiometer system consisted of a dual polarization total power radiometer operating at the center frequency of $6.7 \mathrm{GHz}$ housed atop a $10 \mathrm{~m}$ tower installed on a 16 trailer bed. UFCMR was designed and built by the Microwave Geophysics Group at the University of Michigan. It operates at the center frequency at $6.7 \mathrm{GHz}$ which is identical to one of the center frequencies on the space borne Advanced Microwave Scanning Radiometer (AMSR) aboard the NASA Aqua Satellite Program. UFCMR observed the $11 \mathrm{~m} \mathrm{X} 11 \mathrm{~m}$ from a height of $7.6 \mathrm{~m}$. A rotary system was used to rotate the look angle of the UFCMR both for field observations and sky measurements. The brightness temperatures were observed at an incidence angle of 55matching that of the space borne AMSR-E sensor. The radiometer was calibrated every two weeks with a microwave absorber as warm load and measurements of sky at several angles as cold load. Figure 4 (b) and 4 (c) show the close-up of the antenna and the rotary system of the UFCMR, respectively. Table 1 lists the specifications of UFCMR. Figure A-1 shows the V$\&$ H-pol brightness temperatures observed during MicroWEX-1.

\subsubsection{Theory of operation}

UFCMR uses a thermoelectric cooler (TEC) for thermal control of the Radio Frequency (RF) stages for the UFCMR. This is accomplished by the Oven Industries "McShane" thermal controller. McShane is used to cool or heat by Proportional-Integral-Derivative (PID) algorithm

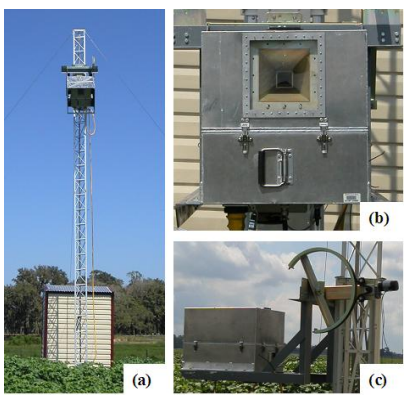

Figure 4. (a) The UFCMR system, (b) the front view showing the receiver antenna, and (c) the side side view showing the rotary system. Credits: Calvin Tien

with a high degree of precision at $0.01{ }^{\circ} \mathrm{C}$. The aluminum plate to which all the RF components are attached is chosen to have sufficient thermal mass to eliminate short-term thermal drifts. All components attached to this thermal plate, including the TEC, use thermal paste to minimize thermal gradients across junctions.

The majority of the gain in the system is provided by a gain and filtering block designed by the University of Michigan for the STAR-Light instrument (De Roo, 2003). The main advantage of this gain block is the close proximity of all the amplifiers, simplifying the task of thermal control. This gain block was designed for a radiometer working at the radio astronomy window of 1400 to $1427 \mathrm{MHz}$, and so the receiver is a heterodyne type with downconversion from the C-band RF to L-band. To minimize the receiver noise figure, a $\mathrm{C}$-band low-noise amplifier (LNA) is used just prior to downconversion. To protect the amplifier from saturation due to out of band interference, a relatively wide bandwidth, but low insertion loss, bandpass filter is used just prior to the amplifier. Between the filter and the antenna are three components: a switch for choosing polarization, a switch for monitoring a reference load, and an isolator to minimize changes in the apparent system gain due to differences in the reflections looking upstream from the LNA.

The electrical penetrations use commercially available weatherproof bulkhead connections (Deutsch connectors or equivalent). The heat sinks have been carefully located employing RTV (silicone sealant) to seal the bolt holes. The radome uses $15 \mathrm{mil}$ polycarbonate for radiometric signal penetration. It is sealed to the case using a rubber gasket held down to the case by a square retainer. 
The first SMA connection electomechanical latching, which is driven by the Z-World control board switches between $\mathrm{V}$ - and H-polarization sequentially. The SMA second latching which switches between the analog signal from the first switch and the reference load signal from a reference load resistor sends the analog signal to a isolator, where the signal within 6.4 to $7.2 \mathrm{GHz}$ in radiofrequency are isolated. Then the central frequency is picked up by a $6.7 \mathrm{GHz}$ bandpass filter, which also protects the amplifier to saturation. A Low Noise Amplifier (LNA) is used to eliminate the noise figure and adjust gain. A mixer takes the input from the LNA and a local oscillator to output a $1.4 \mathrm{GHz}$ signal to STAR-Lite. After the Power Amplifier and Filtering Block (Star-Lite back-end), the signal is passed through a Square Law Detector and a Post-Detection Amplifier. UFCMR is equipped with a microcontroller that has responsibility for taking measurements, monitoring the thermal environment, and storing data until a download is requested. A labtop computer is used for running the user interface named FluxMon to communicate with the radiometer through Radiometer Control Language (RadiCL). The radiometer is configured to maintain a particular thermal set point, and make periodic measurements of the brightness at both polarizations sequentially and the reference load. The data collected by the radiometer is not calibrated within the instrument, since calibration errors could corrupt an otherwise useful dataset. Figure 8 shows the block diagram of UFCMR.

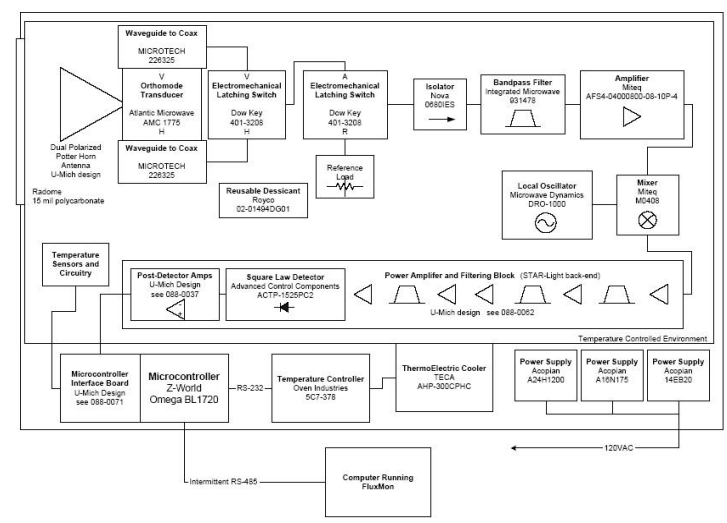

Figure 5. Block diagram of the UFCMR (De Roo, 2002).

\subsection{Eddy Covariance System}

A Campbell Scientific eddy covariance system borrowed from Dr. Jennifer Jacobs, University of New Hampshire was located at the southeast corner of the field also shown in Figure 3. The system included a CSAT3 anemometer and $\mathrm{KH} 20$ hygrometer. CSAT3 is a three dimensional sonic anemometer, which measures wind speed and the speed of sound on three nonorthogonal axes. Orthogonal wind speed and sonic temperature are computed from these measurements. KH20 measures the water vapor in the atmosphere. It output voltage is proportional to the water vapor density flux. Latent and sensible heat fluxes were measured every 30 minutes. The height of the eddy covariance system was $2.1 \mathrm{~m}$ from the ground and the orientation of the system was 209 toward southwest. Table 2 shows the list of specifications of the CSAT3. Data collected by the eddy covariance system have been corrected for coordinate rotation (Kaimal and Finnigan, 1994; Wilczak et al., 2001), WPL (Web et al., 1980), oxygen (van Dijk et al., 2003), and sonic temperature corrections (Schotanus et al., 1983). Figure A-2 shows the latent and sensible heat fluxes observed during MicroWEX-1.

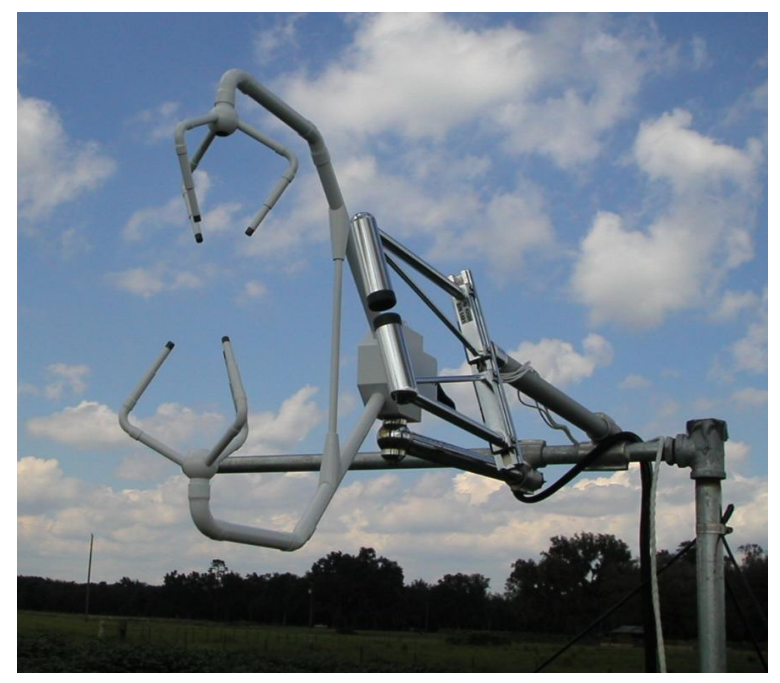

Figure 6. Eddy covariance system. Credits: Calvin Tien

\subsection{Net Radiometer}

A Kipp and Zonen CNR-1 four-component net radiometer (Figure 7) was located at the center of the field to measure up- and down-welling short- and long-wave infrared radiation. The sensor consists of two pyranometers (CM-3) and two pyrgeometers 
(CG-3). The sensor was installed at the height of 2.5 $\mathrm{m}$ above ground and facing south. Table 3 shows $\mathrm{s}$ the list of specifications of the CNR-1 net radiometer. Figure A-3 shows the up- and down-welling solar (shortwave) wave radiation observed during MicroWEX-1. Figure A-4 shows the up- and down-welling far infrared (longwave) radiation observedduringMicroWEX-1. Figure A-5 shows the net total radiation observed during MicrWEX-1. Figure A-6 shows the solar albedo observed during MicroWEX-1.

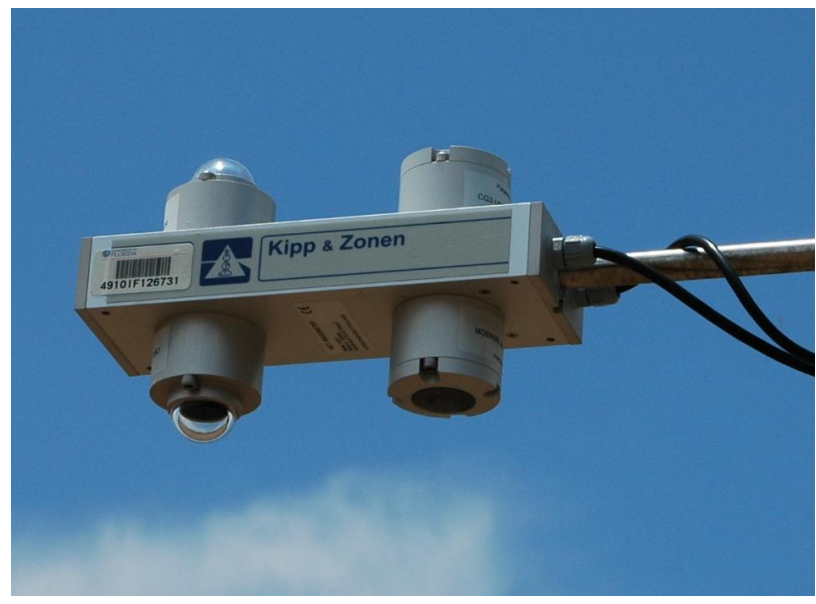

Figure 7. CNR-1 net radiometer. Credits: Calvin Tien

\subsection{Thermal Infrared Sensor}

An Everest Interscience thermal infrared sensor (4000.3ZL) was collocated with the net radiometer to observe skin temperature at nadir. The sensor was installed at the height of $2.5 \mathrm{~m}$. With the sensor field of view of $15^{\circ}$, the size of the footprint for the thermal infrared sensor was $66 \mathrm{~cm} \mathrm{X} 66 \mathrm{~cm}$. Figure A-7 shows the surface thermal infrared temperature observed during MicroWEX-1.

\subsection{Soil Moisture and Temperature Probe}

Five standard Vitel Hydra soil moisture and temperature probes and five Campbell Scientific time-domain water content reflectometer (CS616) were used to measure soil volumetric water content and temperature of $4,8,12$, and $20 \mathrm{~cm}$ in row every 15 minutes. The observations were duplicated at the depth of $4 \mathrm{~cm}$ near the root zone. The calibration coefficients for the CS616 probes are listed in Table 2. Figure A-8 and 9 show the volumetric soil moisture content observed $b$ the Hydra and TDR probes during MicroWEX-1, respectively. Figure 10 shows the volumetric soil moisture content observed at $4 \mathrm{~cm}$ in the middle of two rows and near the root area by the Hydra and TDR probes during MicroWEX-1, respectively. Figure A-11 shows the soil temperatures observed by the Hydra probes during MicroWEX-1. Figure A-12 shows the soil temperatures observed at $4 \mathrm{~cm}$ in the middle of two rows and near the root area by the Hydra probes during MicroWEX-1.

\subsection{Soil Heat Flux Plate}

Two Campbell Scientific soil heat flux plate (HFT-3) were used to measure soil heat flux at the depths of 4 and $8 \mathrm{~cm}$, in row and near the root area, respectively. Figure A-13 shows the soil heat fluxes observed during MicroWEX-1.

\subsection{Florida Automated Weather Network (FAWN)}

Data from one of the Florida Automated Weather Network (FAWN) sites (http://fawn.ifas.ufl.edu) were also available during the MicorWEX-1. Four raingauges were used to collect precipitation and irrigation across the study site, as shown in Figure 3. Table 7 shows the parameters measured by FWAN. Figure A-14 shows the air temperature observed during MicroWEX-1. Figure A-15 shows the soil temperatures at $10 \mathrm{~cm}$ observed during MicroWEX-1. Figure A-16 shows the net total radiation observed during MicroWEX-1. Figure A-17 shows the wind directions observed during MicroWEX-1. Figure A-18 shows the relative humidity observed during MicroWEX-1. Figure A-19, 20 and 21 show the rainfall observed during MicroWEX-1.

\section{SOIL SAMPLING}

Extensive soil sampling was conducted to provide additional information of the spatial distribution of the surface soil moisture, temperature, and surface roughness. The locations of the soil sampling sites are shown in Figure 3.

\subsection{Gravimetric Soil Moisture}

The gravimetric soil moisture (GSM) was sampled at $0-4,4-8,8-12$, and $12-20 \mathrm{~cm}$ by a coring tool. By knowing the diameter of the inside cylinder 
of the coring tool, which was $4.3 \mathrm{~cm}$ in diameter, the GSM was converted to VSM by bulk density as follows,

$$
\begin{aligned}
& V S M=G S M \times\left(\frac{r h o_{B}}{r h o_{w}}\right) \\
& r h o_{B}=\frac{w_{s}}{V_{s}}
\end{aligned}
$$

where rho is the density of water which is 1000 $\mathrm{kg} / \mathrm{m}^{3}, \mathrm{rho}_{\mathrm{B}}$ is bulk density which is aprroximately $1300 \mathrm{~kg} / \mathrm{m}^{3}$ for the sandy soil, $w_{s}$ is the weight of the soil, and $V_{s}$ is the volume of the soil. Figure A-22 and 23 show the volumetric soil moisture content derived by the gravimetric soil samples measured during MicroWEX-1.

\subsection{Soil Temperature}

A Max/Min waterproof digital thermometer from Forestry Supplier was used to measure the soil temperature at the depths of $2,4,8$, and $16 \mathrm{~cm}$ at the same locations and time as the soil moisture sampling. The near surface soil temperature especially at the depth of $2 \mathrm{~cm}$ changed rapidly. This was primarily due to the canopy cover was not uniform throughout the field. Figure A-24 and 25 show the soil temperature observed during MicroWEX-1.

\section{VEGETATION SAMPLING}

Vegetation properties such as stand density, row spacing, height, biomass, and LAI were measured weekly during the field experiment. The crop density derived from the stand density and row spacing was measured at the first two sampling since the cotton seeds were planted in the fixed spacing and the germination rate is over $90 \%$ throughout the field. The specific bi-weekly measurements include height, biomass, and LAI. In the early season, the first four vegetation samplings were conducted on seven spatially distributed sampling locations (Figure 3). It was designed to characterize the spatial variability of the vegetation properties in the study site on July 29, July 31, August 8, and August 17. After that, one vegetation sampling location was chosen to better represent the crop height within the radiometer footprint at least 30 meters from the field boundary.

\subsection{Height}

Crop height was measured by placing a measuring tape at the soil surface to average height of the crop. The height inside the UFCMR footprint and at the vegetation sampling area were taken for each vegetation sampling. Figure A-26 shows the crop height observed during MicroWEX-1.

\subsection{Leaf Area Index (LAI)}

LAI of the footprint was approximated by measuring 24 locations around the footprint every week. A Sunscan canopy analysis system was used for the first two LAI samplings and was out of order due to a loose connection between the measuring unit and the hand-held data-recording unit on August 24 (DoY 236). After that, LAI was measured with a Li-Cor LAI-2000 in the inter-row region with 4 cross-row measurements. The LAI-2000 was set to average 4 locations into a single value so one observation was taken above the canopy and 4 beneath the canopy; in the row, $1 / 4$ of the way across the row, $1 / 2$ of the way across the row, and $3 / 4$ of the way across the row. This gave a spatial average for row crops of partial cover. Figure A-28 shows the LAI observed during MicroWEX-1.

\subsection{Green and Dry Biomass}

Each vegetation sampling was conducted one row. The sampling length was measured the same as during stand density measurement. The plants within this length were pulled out and put in plastic bags to prevent losing moisture. In the laboratory, the canopy samples were separated into leaves, stems, and bolls to measure their wet weights. The vegetation samples were put into paper bags and dried in the oven at $75^{\circ} \mathrm{C}$ for 48 hours. Then the vegetation samples were removed from the oven and the dry weights were measured. Figure A-27 shows the Green biomass observed during MicroWEX-1. At the end of the field experiment, the cotton lint yield was estimated to be $32000 \mathrm{~kg} / \mathrm{ha}$.

\section{FIELD LOG}

Note: Time is in Eastern Standard Time. 
July 8 (DoY 189)

09:00 Measured the field dimensions.

$$
\underline{\text { July } 9 \text { (DoY 190) }}
$$

15:15 Planting (at the depth of 3-4 cm with $4 \mathrm{~cm}$ crop spacing and $90 \mathrm{~cm}$ in row spacing).

Applied pesticide.

$\underline{\text { July } 15 \text { (DoY 196) }}$

08:00 Moved the linear move in the field for sensor installation.

$\underline{\text { July } 17 \text { (DoY 198) }}$

09:00 Set up all sensors and field instruments.

$$
\underline{\text { July } 21 \text { (DoY 202) }}
$$

11:30 The connection between STAR-Lite and coaxial tunnel diode detector was found loose which caused the lost of ouput signal from the detector. Larry soldered the loose connection.

Readjusted the gain and offset of the PDA, after adjustment $\sim 0.7$ volt at sky and 2.1 volt at absorber.

Start to collect radiometer data.

$\underline{\text { July } 23 \text { (DoY 204) }}$

09:00 Conducted vegetation sampling (incomplete due to thunder storm).

$\underline{\text { July } 24 \text { (DoY 205) }}$

08:00 Conducted vegetation sampling.

11:45 Power was out due to the thunder storm since 12:45, July 24.

$\underline{\text { July } 25 \text { (DoY 206) }}$

12:10 Restarted data recording.

$\underline{\text { July } 27 \text { (DoY 208) }}$

06:00 Power was out since 09:36, July 27.

09:05 Restarted data recording.
July 29 (DoY 210)

09:30 Conducted surface roughness measurements.

11:40 Conducted soil and vegetaion sampling.

$\underline{\text { July } 31 \text { (DoY 212) }}$

08:50 Irrigation.

Conducted soil and vegetation sampling.

August 2 (DoY 214)

08:20 Conducted soil smpling.

\section{$\underline{\text { August } 4 \text { (DoY 216) }}$}

10:30 Power was out since 14:22, August 2.

\section{August 5 (DoY 217)}

09:05 The connection between STAR-Lite and coaxial tunnel diode detector was found loose which caused the lost of output signal from the detector. Larry soldered the loose connection.

Restarted data recording.

August 6 (DoY 218)

10:00 Marked the location for eddy covariance system.

August 8 (DoY 220)

05:40 Power was out since 16:33, August 7.

06:25 Conducted soil and vegetation sampling.

08:00 Restarted data recording.

10:00 Removed the TIR sensor due to moisture damage.

August 10 (DoY 222)

09:45 Conducted radiometer calibration.

10:20 Restarted data recording.

$\underline{\text { August } 13 \text { (DoY 223) }}$ 
Power was out snce 07:18, August 13.

August $12($ DoY 224)

15:55 Restarted data recording.

August 13 (DoY 225)

08:15 Measured the offset voltage of the PDA $(-0.845$ volt $)$.

Conducted radiometer calibration.

$\underline{\text { August } 15 \text { (DoY 227) }}$

08:45 Installed eddy covariance system.

CSAT direction was changed from -20 o ro 180 o.

Loaded program Fluxtien.csi to the eddy covariance system.

$\underline{\text { August } 17(\text { DoY 229) }}$

08:45 Conducted vegetation sampling.

August 18 (DoY 230)

09:20 Power wa out since 17:34, August 17.

Conducted vegetation sampling.

$\underline{\text { August } 19 \text { (DoY 231) }}$

08:30 Added one soil heat flux plate at $8 \mathrm{~cm}$ close to root zone.

Restarted data recording.

22:30 Power was out since 8:33, August 19.

$\underline{\text { August } 21 \text { (DoY 233) }}$

09:30 Restarted data recording.

09:50 Installed HOBO raingauges at the east and west edges of the radiometer footprint.

$\underline{\text { August } 24 \text { (DoY 236) }}$

09:00 Conducted vegetation sampling.

16:30 Power was out since 16:28, August 24.
August 26 (DoY 238)

14:00 Restarted data recording.

Conducted soil sampling.

August 27 (DoY 239)

09:10 Power was out since 09:09, August 27.

August 28 (DoY 240)

08:30 Restarted data recording.

10:10 Conducted radiometer calibration.

August 31 (DoY 243)

09:00 Restarted data recording.

09:10 Conducted vegetation sampling.

$\underline{\text { September } 1 \text { (DoY 244) }}$

16:00 Power was out since 15:59, September 1.

September 2 (DoY 245)

09:00 Restarted data recording.

September 4 (DoY 247)

08:40 Conducted soil sampling.

14:50 Ceased data recording due to incoming thunder torm.

$\underline{\text { September } 5 \text { (DoY 248) }}$

14:10 Restarted data recording.

September 7 (DoY 250)

09:45 Conducted vegetation sampling.

$\underline{\text { September } 11 \text { (DoY 254) }}$

09:00 Replaced KH20 due to water damage.

$\underline{\text { September } 14 \text { (DoY 257) }}$

08:00 Conducted vegetation sampling.

$\underline{\text { September } 16 \text { (DoY 259) }}$ 
08:00 Conducted radiometer calibration.

$\underline{\text { September } 18 \text { (DoY 261) }}$

07:00 Irrigation.

September 21 (DoY 264)

08:30 Conducted vegetation sampling.

September 25 (DoY 268)

08:45 Conducted soil sampling.

$\underline{\text { September } 28 \text { (DoY 271) }}$

08:45 Conducted vegetation sampling.

September 30 (DoY 273)

08:50 Conducted radiometer calibration.

$\underline{\text { October } 1 \text { (DoY 274) }}$

13:20 Tested the Hydra probes.

October 2 (DoY 275)

11:00 Irrigation.

October 5 (DoY 278)

09:00 Conducted vegetaion sampling.

October 9 (DoY 282)

10:00 Tested the Hydra probes. Data gap since 12:00, August 4. Hydra probes were damaged due to lightning strike.

\section{October 12 (DoY 285)}

09:30 Conducted vegetation sampling.

October 14 (DoY 287)

09:30 Conducted radiometer calibration.

October 15 (DoY 288)

09:30 Installed TDR and Hydra probes at the center of the field.

October 16(DoY 289)
12:15 Installed TIR sensor.

October 19 (DoY 292)

08:30 Conducted vegetation sampling.

October 28 (DoY 301)

08:20 Conducted radiometer calibration.

October 30 (DoY 303)

10:00 Conducted soil sampling.

$\underline{\text { November } 2 \text { (DoY 306) }}$

09:30 Conducted vegetation sampling.

$\underline{\text { November } 9 \text { (DoY 313) }}$

10:30 Conducted vegetation sampling.

$\underline{\text { November } 11 \text { (DoY 315) }}$

10:00 Conducted radiometer calibration.

$\underline{\text { November } 16 \text { (DoY 320) }}$

10:00 Conducted vegetation sampling.

November 20 (DoY 324)

09:00 Conducted soil sampling.

November 23 (DoY 327)

09:00 Conducted vegetation sampling.

$\underline{\text { November } 25 \text { (DoY 329) }}$

10:00 Conducted radiometer calibration.

December 9 (DoY 343)

09:30 Conducted radiometer calibration.

$\underline{\text { December } 11 \text { (DoY 345) }}$

10:00 Conducted vegetation sampling.

$\underline{\text { December } 16 \text { (DoY 349) }}$

08:00 Conducted vegetation sampling at the radiometer footprint. 
Conducted surface roughness measurement at the radiometer footprint.

Conducted soil sampling at the radiometer footprint.

Finished the fieldexperiment.

January 7, 2004 (DoY 7)

Harvested the cotton.

\section{REFERENCES}

Campbell Scientific, CSAT3 Three Dimensional Sonic Anemometer Instruction Manual, Campbell Scientific Inc., Logan, UT, 1998.

Campbell Scientific, HFT3 soil heat flux plate instruction manual, Campbell Scientific Inc., Logan, UT, 2003.

Campbell Scientific, CNR1 Net Radiometer Instruction Manual, Campbell Scientific Inc., Logan, UT, 2004a.

Campbell Scientific, CS615 andCS625 water content reflectometers instruction manual, Campbell Scientific Inc., Logan, UT, 2004b.

Everest Interscience, Model 4000.3ZL Infrared Temperature Sensor, Everest Interscience Inc., Tuson, AZ, 2005.

J. C. Kaimal and J. J. Finnigan, Atmospheric Boundary Layer Flows, Oxford University Press, New York, NY, 1994.

R. D. De Roo, University of Florida C-band Radiometer Summary, Space Physics Research Laboratory, University of Michigan, Ann Arbor, MI, March, 2002.

\section{R. D. D Roo, TMR-3 Radiometer Tuning} Procedures, Space Physics Research Laboratory, University of Michigan, Ann Arbor, MI, March, 2003.

P. Schotanus, F. T. M. Nieuwstadt, and H. A. R. DeBruin, "Temperature measurement with a sonic anemometer and its application to heat and moisture fluctuations," Bound.-Layer Meteorol., vol. 26, pp. 81-93, 2003.
A. van Dijk, W. Kohsiek, and H. A. R. DeBruin, "Oxygen sensitivity of krypton and Lyman-alpha hygrometer," J. Atmos. Ocean. Tech., vol. 20, pp. 143-151., 2003.

A. van Dijk, A. F. Moene, and H. A. R. DeBurin, The Principles of Surface Flux Physics: Theory, Practice, and Description of the ECPACK Library, http://www.met.wau.nl/projects/jep/

E. K. Webb, G. I. Pearman, and R. Leuning, “ Correction of flux measurements for density effects due to heat and water vapor transfer," Quart. J. Roy. Meteorol., Soc., vol. 106, pp. 85-100, 1980.

J. M. Wilczak, S. P. Oncley, and S. A. Stage, "Sonic anemometer tilt correction algorithms," Bound.-Layer Meteorol., vol. 99, pp. 127-150, 2001.

\section{A. FIELD OBSERVATIONS}
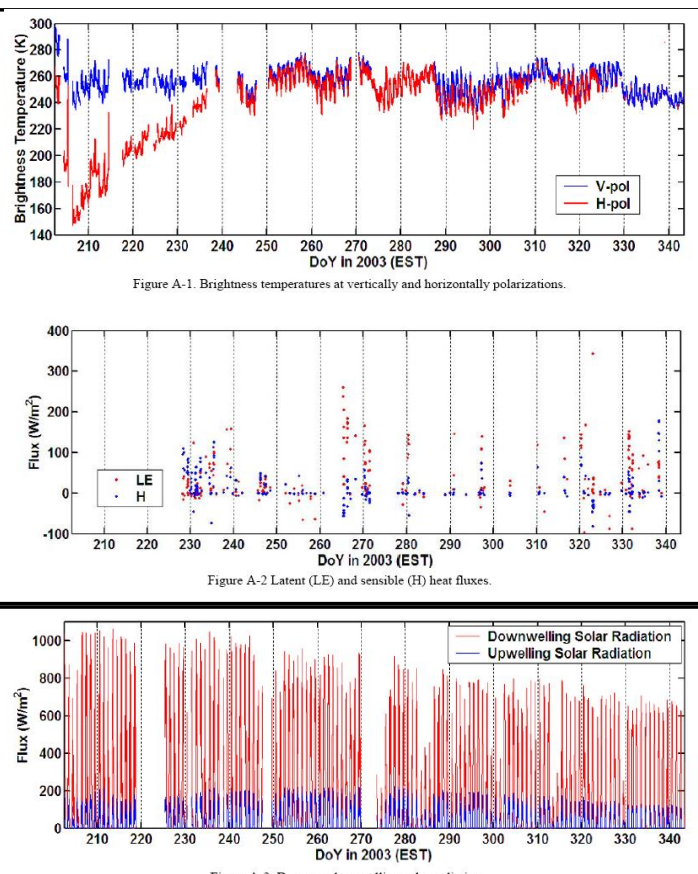

Figure A-3. Down- and up-welling solar radiatio

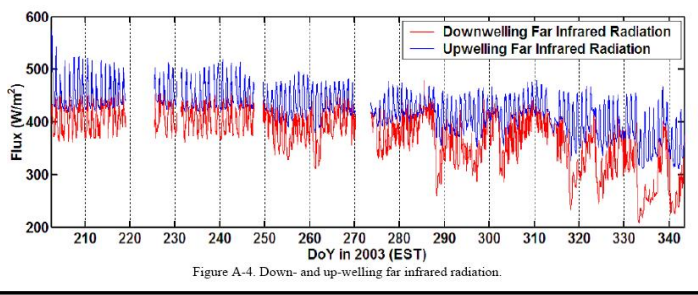



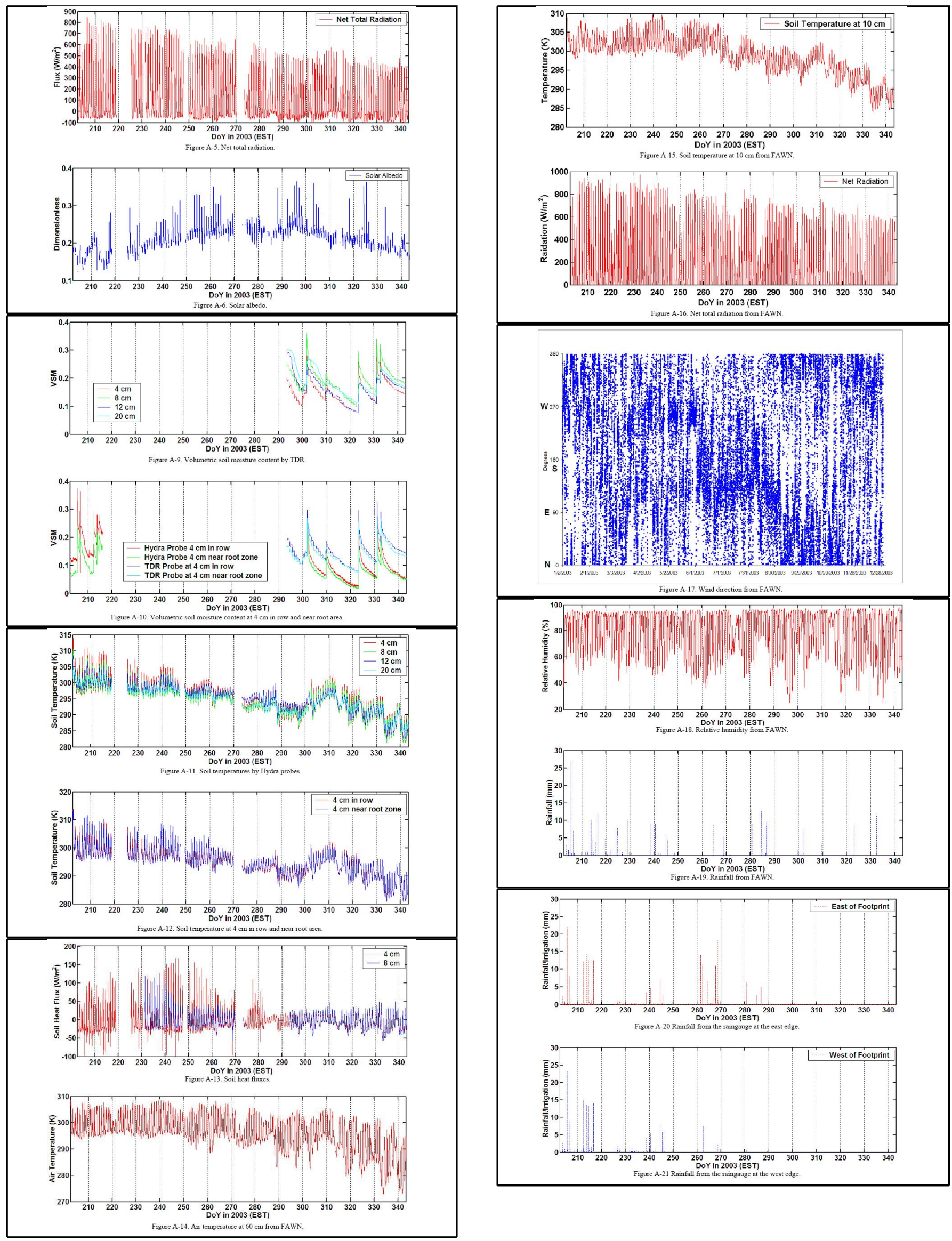

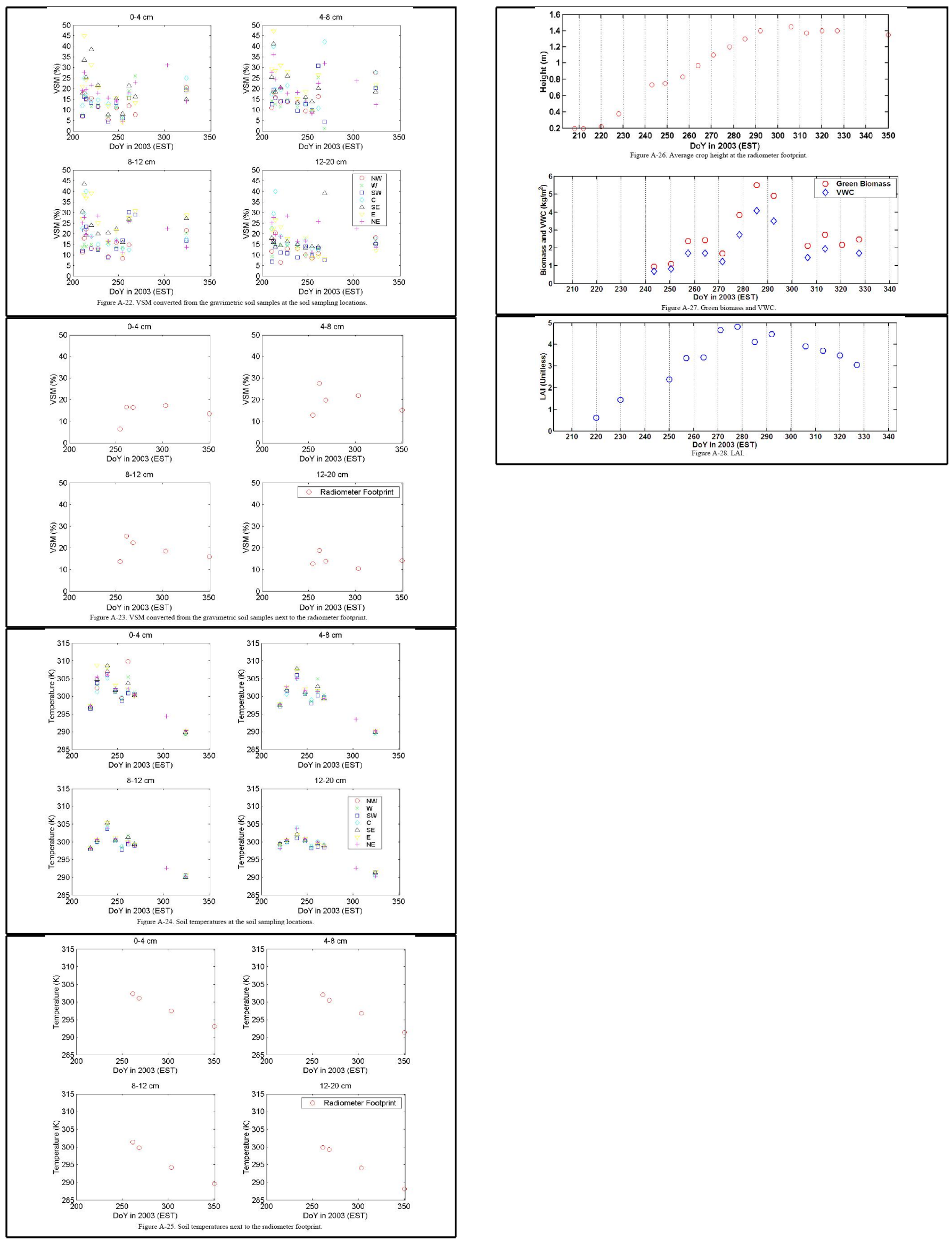
Table 1. UFCMR specifications

\begin{tabular}{||l|l|l||}
\hline \hline Parameter & Qualifier & Value \\
\hline Frequency & Center & $6.7 \mathrm{GHz}$ \\
\hline Bandwidth & $3 \mathrm{~dB}$ & $20 \mathrm{MHz}$ \\
\hline & $3 \mathrm{~dB}$ V-pol elevation & $23^{\circ}$ \\
\hline & $3 \mathrm{~dB}$ V-pol azimuth & $21^{\circ}$ \\
\hline & $3 \mathrm{~dB} \mathrm{H}$-pol elevation & $21^{\circ}$ \\
\hline & $3 \mathrm{~dB}$-pol azimuth & $23^{\circ}$ \\
\hline Isolation & & $>27 \mathrm{~dB}$ \\
\hline Polarizations & Sequential & $\mathrm{V} / \mathrm{H}$ \\
\hline Receiver temp & & $437 \mathrm{~K}$ \\
\hline Noise Figure & From Trec & $3.99 \mathrm{~dB}$ \\
\hline RF gain & & $85 \mathrm{~dB}$ \\
\hline Gain tempco & $\mathrm{dTsys} / \mathrm{dT}$ Tset & $-2 \mathrm{~K} /{ }^{\circ} \mathrm{C}$ \\
\hline NEDT & $1 \mathrm{sec}$ & $0.71 \mathrm{~K}$ \\
\hline & $8 \mathrm{sec}$ & $0.25 \mathrm{~K}$ \\
\hline Temperature & Control - rms & $5 \mathrm{mK}$ \\
\hline SetPoint & Max & $40^{\circ} \mathrm{C}$ \\
\hline & Min & $0^{\circ} \mathrm{C}$ \\
\hline Ambient & Max & $48^{\circ} \mathrm{C}$ \\
\hline & Min & $<0{ }^{\circ} \mathrm{C}$ \\
\hline RF cutout & McShane or RF1 thermistor & $42^{\circ} \mathrm{C}$ \\
\hline $\begin{array}{l}\text { Thermal } \\
\text { shutdown }\end{array}$ & Case thermistor & $62^{\circ} \mathrm{C}$ \\
\hline \hline
\end{tabular}

Table 2. Specifications of the CSAT3 (Campbell Scientific, 1998)

\begin{tabular}{|c|c|}
\hline Description & Value \\
\hline Measurement rate & 1 to $60 \mathrm{~Hz}$ \\
\hline Noise equivalent wind & $1 \mathrm{~mm} / \mathrm{sec}$ in horizontal wind speed and $0.5 \mathrm{~mm} / \mathrm{sec}$ in vertical wind speed \\
\hline Wind measurement offset & $< \pm 4 \mathrm{~cm} / \mathrm{sec}$ over -30 to $50^{\circ} \mathrm{C}$ \\
\hline Output signals & Digital SDM or RS-232 and Analog \\
\hline Digital output signal range & $\pm 65.535 \mathrm{~m} / \mathrm{sec}$ in wind speed and 300 to $366 \mathrm{~m} / \mathrm{sec}$ in speed of sound \\
\hline Digital output signal resolution & 0.25 to $2 \mathrm{~mm} / \mathrm{sec}$ in vertical wind speed and $1 \mathrm{~mm} / \mathrm{s}$ in speed of sound \\
\hline Analog output signal range & \pm 32.768 to $\pm 65.536 \mathrm{~m} / \mathrm{sec}$ in wind speed and 300 to $366 \mathrm{~m} / \mathrm{sec}$ in speed of sound \\
\hline Analog output signal resolution & $\pm 8.192 \mathrm{~mm} / \mathrm{sec}$ in vertical wind speed and $16 \mathrm{~mm} / \mathrm{sec}$ in speed of sound \\
\hline Measurement path length & $10.0 \mathrm{~cm}$ vertical and $5.8 \mathrm{~cm}$ horizontal \\
\hline Transducer path angle from horizontal & 60 degrees \\
\hline Transducer & $0.64 \mathrm{~cm}$ in diameter \\
\hline Transducer mounting arms & $0.84 \mathrm{~cm}$ in diameter \\
\hline Support arms & $1.59 \mathrm{~cm}$ in diameter \\
\hline Dimensions: anemometer head & $47.3 \mathrm{~cm} \times 42.4 \mathrm{~cm}$ \\
\hline Dimensions: electronics box & $26 \mathrm{~cm} \times 16 \mathrm{~cm} \times 9 \mathrm{~cm}$ \\
\hline Dimensions: carry case & $71.1 \mathrm{~cm} \times 58.4 \mathrm{~cm} \times 33 \mathrm{~cm}$ \\
\hline Weight: anemometer head & $1.7 \mathrm{~kg}$ \\
\hline Weight: electronics box & $2.8 \mathrm{~kg}$ \\
\hline Weight: shipping & $16.8 \mathrm{~kg}$ \\
\hline
\end{tabular}


Field Data Report for the First Microwave Water and Energy Balance Experiment....

Table 2. Specifications of the CSAT3 (Campbell Scientific, 1998)

\begin{tabular}{||l|l||}
\hline \hline Operating temperature range & $-30^{\circ} \mathrm{C}$ to $50^{\circ} \mathrm{C}$ \\
\hline Power requirement: voltage supply & 10 to $16 \mathrm{VDC}$ \\
\hline Power requirement: current & $200 \mathrm{~mA}$ at $60 \mathrm{~Hz}$ measurement rate and $100 \mathrm{~mA}$ at $20 \mathrm{~Hz}$ measurement rate \\
\hline \hline
\end{tabular}

Table 3. Specifications of the CNR-1 net radiometer (Campbell Scientific, 2004a)

\begin{tabular}{||l|l||}
\hline \hline Description & Value \\
\hline Measurement spectrum: CM-3 & 305 to \\
& $2800 \mathrm{~nm}$ \\
\hline Measurement spectrum: CG-3 & $5000 \mathrm{to}$ \\
& $50000 \mathrm{~nm}$ \\
\hline Response time & $18 \mathrm{sec}$ \\
\hline Sensitivity & 10 to 35 \\
& $\mu \mathrm{V} /(\mathrm{W} / \mathrm{m}$ \\
\hline Pt-100 sensor temperature measurement & DIN class \\
& $\mathrm{A}$ \\
\hline Accuracy of the Pt-100 measurement & $\pm 2 \mathrm{~K}$ \\
\hline Heating & Resistor \\
& $24 \mathrm{ohms}$, \\
& $6 \mathrm{VA}$ at 12 \\
\hline Maximum error due to heating: CM-3 & $10 \mathrm{~W} / \mathrm{m}^{2}$ \\
\hline Operating temperature & $-40^{\circ}$ to \\
\hline Daily total radiation accuracy & $70^{\circ} \mathrm{C}$ \\
\hline Cable length & $\pm 10 \%$ \\
\hline Weight & $10 \mathrm{~m}$ \\
\hline \hline & $4 \mathrm{~kg}$ \\
\hline
\end{tabular}

Table 4. Specifications of the thermal infrared sensor (Everest Interscience, 2005)

\begin{tabular}{||l|l||}
\hline \hline Description & Value \\
\hline Accuracy & $\pm 0.5^{\circ} \mathrm{C}$ \\
\hline Resolution & $0.1^{\circ} \mathrm{C}$ \\
\hline Measurement range & $-40^{\circ}$ to $100^{\circ} \mathrm{C}$ \\
\hline Measurement spectrum & 8 to $14 \mu \mathrm{m}$ \\
\hline Field of view & $15^{\circ}$ \\
\hline Response time & $0.1 \mathrm{sec}$ \\
\hline Operating distance & $2 \mathrm{~cm}$ to $300 \mathrm{~m}$ \\
\hline Power requirement: voltage supply & 5 to $26 \mathrm{VDC}$ \\
\hline Power requirement: current & $10 \mathrm{~mA}$ \\
\hline Output signal & $\mathrm{RS}-232 \mathrm{C}$ and analog $\mathrm{mV}$ \\
& $\left(10.0 \mathrm{mV} /{ }^{\circ} \mathrm{C}\right)$ \\
\hline \hline
\end{tabular}


Table 5. The calibration coefficients for the CS616 probes

(Campbell Scientific, 2004b)

\begin{tabular}{||l|l||}
\hline \hline Coefficient & Value \\
\hline$C$ & -0.187 \\
\hline$C_{2}$ & 0.037 \\
\hline$C_{2}$ & 0.335 \\
\hline \hline
\end{tabular}

Table 6. Specifications of the soil heat flux plate (Campbell Scientific, 2003)

\begin{tabular}{||l|l||}
\hline \hline Description & Value \\
\hline Operating temperature & $-40^{\circ}$ to $55^{\circ} \mathrm{C}$ \\
\hline Plate thickness & $3.91 \mathrm{~mm}$ \\
\hline Plate diameter & $38.2 \mathrm{~mm}$ \\
\hline Sensor & Thermopile \\
\hline Measurement range & $\pm 100 \mathrm{~W} / \mathrm{m}^{2}$ \\
\hline Signal range & $\pm 2.4 \mathrm{mV}$ \\
\hline Accuracy & $\pm 5 \%$ \\
\hline Thermal conductivity & $1.22 \mathrm{~W} / \mathrm{m} / \mathrm{K}$ \\
\hline \hline
\end{tabular}

Table 7. Micrometeorological parameters measured by the FAWN station.

\begin{tabular}{||l|l||}
\hline \hline Parameter & Unit and Description \\
\hline Air temperature & ${ }^{\circ} \mathrm{C}$, at $60 \mathrm{~cm}$ \\
\hline Soil temperature & ${ }^{\circ} \mathrm{C}$, at $10 \mathrm{~cm}$ \\
\hline Rainfall & $\mathrm{mm}$ \\
\hline Relative humidity & $\%$ \\
\hline Solar radiation & $\mathrm{W} / \mathrm{m}^{2}$ \\
\hline Wind speed & $\mathrm{m} / \mathrm{sec}$, at $10 \mathrm{~m}$ \\
\hline Wind direction & ${ }^{\circ}$, at $10 \mathrm{~m}$ \\
\hline \hline
\end{tabular}

